\title{
EFFECT OF 2\% CHLORHEXIDINE GLUCONATE ON THE DEGRADATION OF RESIN COMPOSITE-DENTIN BOND STRENGTH WHEN USING SELF-ETCH ADHESIVE SYSTEMS
}

\author{
DEWI PUSPITASARI, ELLYZA HERDA*, ANDI SOUFYAN
}

Department of Dental Materials, Faculty of Dentistry, Universitas Indonesia, Jakarta, Indonesia. Email: ellyza_herda@yahoo.com

Received: 16 September 2017, Revised and Accepted: 3 October 2017

ABSTRACT

Objective: The purpose of this study was to analyze the effect of $2 \%$ chlorhexidine gluconate (CHX) on the degradation of composite resin-dentin bond strength when using self-etch adhesive systems.

Methods: CHX (2\%) was applied before application of two-step self-etch (TSC) and one-step self-etch (OSC) adhesive. Resin composite was applied incrementally. Specimens from the degradation treatment group were immersed in $10 \% \mathrm{NaOCl}$ for $1 \mathrm{~h}$. Shear bond strength was tested with a universal testing machine and analyzed using one-way ANOVA and Dunnett's T3 post-hoc test. The composite resin-dentin bonds were observed using scanning electron microscopy (SEM) and energy dispersive spectroscopy (EDS).

Results: In the treatment group without $10 \% \mathrm{NaOCl}$, shear bond strength values were higher in the $2 \% \mathrm{CHX}$-treated group (TSC $11.67 \pm 1.76 \mathrm{MPa}$ and OSC $10.19 \pm 1.44 \mathrm{MPa}$ ) than in the untreated group (TSC $10.93 \pm 1.31 \mathrm{MPa}$ and OSC $9.97 \pm 1.41 \mathrm{MPa}$ ), although this difference was not statistically significant. In samples exposed to $10 \% \mathrm{NaOCl}$, shear bond strength values were higher in the $2 \%$ CHX-treated group (TSC $11.14 \pm 1.22 \mathrm{MPa}$ and 0 SC $9.95 \pm 1.21 \mathrm{MPa}$ ) than in the untreated group (TSC $10.08 \pm 0.45 \mathrm{MPa}$ and OSC $8.62 \pm 0.85 \mathrm{MPa}$ ), although this difference was not statistically significant. The SEM of samples from the $2 \%$ CHX-treated group showed less degradation than samples from the untreated group did.

Conclusion: Application of 2\% CHX may decrease the degradation of the resin composite-dentin bond.

Keywords: $2 \%$ chlorhexidine, Self-etch adhesive systems, Shear bond strength.

(C) 2017 The Authors. Published by Innovare Academic Sciences Pvt Ltd. This is an open access article under the CC BY license (http://creativecommons. org/licenses/by/4. 0/) DOI: http://dx.doi.org/10.22159/ijap.2017.v9s2.12

\section{INTRODUCTION}

Currently, composite resins are widely used for esthetic restoration [1]. However, composite resin restorations may fail in the long term, particularlyat the adhesive resin-dentininterface because ofdegradation processes that occur in the oral cavity [2,3]. Degradation can be caused by hydrolysis due to continuous exposure in water or saliva $[4,5]$. One of the enzymes that contribute to the degradation process of the composite resin-dentin bond is the matrix metalloproteinase (MMP) enzyme [6,7].

The MMP enzyme is a proteolytic enzyme that can degrade collagen fibrils and extracellular matrices in demineralized dentin. This enzyme can be activated by the etching material used in total-etch or self-etch adhesive systems, and thus, can decrease the stability of the collagen matrix. Bonding to dentin is currently achieved using total-etch and self-etch adhesive systems, which vary in the treatment of the smear layer $[8,9]$. Self-etch adhesive systems aim to preserve the smear layer for the resin monomer to diffuse to, and bond the resin monomer to the collagen in the dentin tubule to form a hybrid layer [9]. Self-etch adhesive systems have a simpler application procedure but may reduce dentin sensitivity. Two techniques are used in the application of selfetch adhesive systems: A two-step and a one-step technique. These two techniques differ in the composition and number of application steps [8].

Theoretically, self-etch adhesive systems produce demineralization and monomer infiltration into the dentin substrate simultaneously. However, studies have shown that not all acids can be neutralized. This results in incomplete monomer infiltration and the formation of a demineralization zone below the hybrid layer, which exposes the collagen fibrils $[10,11]$.
Chlorhexidine gluconate ( $\mathrm{CHX}$ ) is used in dental practice as a cavity disinfectant after cavity preparation and before cavity filling [12,13]. It has been extensively studied as an MMP inhibitor for maintaining the hybrid layer in the resin-dentin bond. Dentin collagen fibrils may be degraded by MMP enzymes if they are not coated with resin, which can occur because of deficient infiltration of adhesive monomers $[14,15]$. Application of CHX solution before the priming procedure (self-etch) and after etching (total-etch) brings CHX in contact with the adhesive system [14]. The bond strength of the adhesive system is believed to decrease if CHX interferes with the ability of the hydrophilic monomers to infiltrate dentin properly $[15,16]$. In contrast, other studies have suggested that CHX does not affect the adhesion of the adhesive resin to dentin $[14,17]$.

The long-term stability of the adhesive resin-dentin bond in composite resin restorations can be tested in vitro using an aging method to simulate the degradation of the adhesive resin-dentin bond under conditions occurring in the oral cavity [18]. The most common in vitro method used is immersion in water-based liquid media, which takes months to years.

The $10 \% \mathrm{NaOCl}$ method can significantly reduce the immersion time to as low as a few hours by removing the organic component of the organic collagen fibrils in the dentin matrix $[18,19]$. Immersion in $10 \% \mathrm{NaOCl}$ solution for 1-3 $\mathrm{h}$ can damage some of the collagen fibrils. This pattern also occurs in the degradation of exposed collagen fibrils, since they are not infiltrated by adhesive resins and result in resin hydrolysis [20].

Kim and Shin suggested that CHX could reduce the bond strength of the resin-dentin bond in the total-etch adhesive system during long-term water immersion [21]. Currently, studies on the application of CHX in total-etch adhesive systems have used different CHX concentrations 
and application durations [14]. Thus, limited information is available on the effect of CHX on self-etch adhesive systems, and further research on this particular subject is warranted.

The effect of $2 \%$ CHX on self-etch adhesive systems can be studied by observing the interaction of $2 \%$ CHX with the smear layer and acid primer in self-etch adhesive systems. This is accomplished by analyzing the hybrid layer and resin tag formed between the adhesive resin and dentin and by performing elemental analysis of the composite resin-dentin bond $[22,23]$. This analysis is performed using scanning electron microscopy (SEM) and energy dispersive spectroscopy (EDS) along with a shear bond strength test to assess the strength of the bond between the adhesive system and dentin. The composite resin's durability is evaluated by clarity analysis [24].

Degradation of collagen in dentin due to MMP enzymes should ideally be studied using MMP enzymes, but because of the enzymes' instability and complex utilization procedure, the collagen degradation chemical test is performed using the $10 \% \mathrm{NaOCl}$ immersion method, which is expected to produce the same pattern of collagen degradation as that caused by MMP enzymes $[21,25,26]$.

The objective of the study was to analyze the effect of $2 \%$ CHX solution on the bond strength of composite resin when using two-step self-etch (TSC) and one-step self-etch (OSC) adhesive systems. Adhesive systems that did not receive degradation treatment (baseline bond strength) were compared with systems subjected to degradation treatment by immersion in $10 \% \mathrm{NaOCl}$ for $1 \mathrm{~h}$ to determine the effect on composite resin-dentin bond degradation. This study also aimed to analyze the differences between dentin surfaces treated with $2 \%$ CHX and untreated dentin surfaces, after immersion in $10 \% \mathrm{NaOCl}$ solution.

\section{METHODS}

The materials, their compositions, and the application procedures used are presented in Table 1.

The specimens used were extracted human premolars (indicated for orthodontic treatment) that had been stored in saline solution until used. These non-carious specimens had passed ethical clearance and had no cracks or crown fractures. A total of 64 premolar teeth were cut and planted in a decorative resin, and the buccal surfaces were ground with Struers silicon carbide grinding paper No 600 to obtain an area of $3 \mathrm{~mm}^{2}$. Afterward, the specimens were divided into eight groups (each consisted of eight specimens) for shear bond strength testing. The groups were based on differences in 2\% CHX application, self-etch adhesive system used, and degradation treatment by immersion in $10 \% \mathrm{NaOCl}$ for $1 \mathrm{~h}$. The full description of the classification of specimen groups is listed in Table 2.

Shear bond strength testing was performed using a universal testing machine (Auto Graph AG-5000 E: Shimadzu Corporation, Japan), with a load of $50 \mathrm{kgF}$ and a crosshead speed of $0.5 \mathrm{~mm} / \mathrm{min}$ until the specimen fractured. The results were then calculated with the formula SBS=F/A to obtain shear bond strength with $\mathrm{A}=\pi \mathrm{r}^{2}$. The data were analyzed using a one-way ANOVA test followed by Dunnett's T3 post hoc test.

To capture the SEM and EDS images, we prepared 12 teeth specimens as described in the shear bond strength test. SEM and EDS were used to observe the morphology and analyze the elements on the surface of the resin-dentin interface. Fourteenth specimens were prepared using the following treatment: Abrasion of the teeth, application of 2\% CHX to the abraded teeth, application of TSC primer to the abraded teeth, and application of TSC primer to the abraded teeth treated with CHX $2 \%$. The other eight teeth specimens were prepared according to each group treatment.

\section{RESULTS}

As shown in Table 3, specimens in the TSC with 2\% CHX application and without immersion in $10 \% \mathrm{NaOCl}(11.67 \mathrm{MPa})$ group had the highest mean shear bond strength, whereas the OSC with immersion in $10 \%$ $\mathrm{NaOCl}(8.62 \mathrm{MPa})$ group had the lowest mean shear bond strength.

The mean shear bond strength in the TSC with 2\% CHX application group with or without $10 \% \mathrm{NaOCl}$ immersion was higher than that in the TSC group, although this difference was not statistically significant (Table 3).

The mean shear bond strength in the OSC with 2\% CHX application group with or without $10 \% \mathrm{NaOCl}$ immersion was greater than that in the OSC group, although this difference was not statistically significant (Table 3).

The mean shear bond strength in the TSC group without $10 \% \mathrm{NaOCl}$ immersion was greater than that in the OSC group, although this difference was not statistically significant (Table 3).

The mean shear bond strength in the TSC with $10 \% \mathrm{NaOCl}$ immersion group was significantly greater than that in the OSC with $10 \% \mathrm{NaOCl}$ immersion group (Table 3).

The mean shear bond strengths in each group using TSC with $2 \%$ CHX application, with or without $10 \% \mathrm{NaOCl}$ immersion, were greater than those in the OSC with $2 \%$ CHX group, although this difference was not statistically significant (Table 3). The mean shear bond strength in groups with immersion in $10 \% \mathrm{NaOCl}$ was lower than that in the groups without $10 \% \mathrm{NaOCl}$ immersion, although this difference was not statistically significant (Table 3).

The results of SEM and elemental analysis of the dentin surface are shown in Figs. 1 and 2. The dentin surface that was abraded with No. 600 silicon carbide abrasive paper displayed a smear layer with smear plug

Table 1: Materials, composition, and application procedure used in the study

\begin{tabular}{|c|c|c|c|}
\hline Materials & Manufacturer & Composition & Application procedure \\
\hline \multirow[t]{5}{*}{ Clearfil SE Bond ${ }^{\mathrm{TM}}$} & Kuraray Co. LTD, Osaka, Japan & Primer + Etch: MDP, HEMA, & Apply for $20 \mathrm{~s}$ \\
\hline & & hydrophilic dimethacrylate, photoinitiator, water & Spray light air for $5 \mathrm{~s}$ \\
\hline & & Bonding: 10-MDP, HEMA, Bis-GMA, hydrophobic & Apply bonding agent \\
\hline & & dimethacrylate, photoinitiator, & Spray light air for $5 \mathrm{~s}$ \\
\hline & & silanated colloidal silica & Polymerize with light for $10 \mathrm{~s}$ \\
\hline \multirow[t]{4}{*}{ Clearfil Tri S Bond ${ }^{\mathrm{TM}}$} & Kuraray Co. LTD, Osaka, Japan & Primer + Etch + Bonding: & Applyfor $20 \mathrm{~s}$ \\
\hline & & MDP, Bis-GMA, HEMA, Hydrophobic & Spray light air for $5 \mathrm{~s}$ \\
\hline & & dimethacrylate, champorquinone, ethyl ethanol, & Polymerize with light for $10 \mathrm{~s}$ \\
\hline & & water, silanated colloidal silica & Apply composite resin \\
\hline Consepsis & Ultradent, South Jordan, UT, USA & $2 \% \mathrm{CHX}$ & Using microbrush/tip applicator \\
\hline Filtek Z-350 ${ }^{\mathrm{TM}}$ & 3M ESPE, St. Paul, MN, USA & $\begin{array}{l}\text { Bis-GMA, UDMA, BIS-EMA, Nanosilica filler, } \\
\text { zirconia/silica nanocluster }\end{array}$ & Apply and polymerize for $20 \mathrm{~s}$ \\
\hline
\end{tabular}

MDP: 10-1,10-methacryloyloxydecyl-dihydrogen phosphate, HEMA: 2-hydroxyethyl-ethacrylate, UDMA: Urethane dimethacrylate,

EMA: 2,2-bis-4-2-(hydroxi-3-methylacriloxietoxi)-phenylpropane, GMA: 2,2-bis-4-2-(hydroxi-3-metacriloxiprop-1-oxi) propane, CHX: Chlorhexidine 
Table 2: Description of the groups based on 2\% CHX application and the adhesive system used

\begin{tabular}{lll}
\hline Groups & Number of specimens & Description \\
\hline TSC & 8 & Without CHX, applied with two-step self-etch adhesive system \\
TSC+CHX & 8 & With CHX, applied with two-step self-etch adhesive system \\
OSC & 8 & Without CHX, applied with OSC adhesive system \\
OSC $+\mathrm{CHX}$ & 8 & With CHX, applied with OSC ch adhesive system \\
TSC+NaOCl & 8 & Without CHX, applied with two-step self-etch adhesive system, immersed in $10 \% \mathrm{NaOCl}$ for $1 \mathrm{~h}$ \\
TSC+CHX+NaOCl & 8 & With CHX, applied with two-step self-etch adhesive system, immersed in $10 \% \mathrm{NaOCl}$ for $1 \mathrm{~h}$ \\
OSC+NaOCl & 8 & Without CHX, applied with OSC ch adhesive system, immersed in $10 \% \mathrm{NaOCl}$ for $1 \mathrm{~h}$ \\
OSC+CHX+NaOCl & 8 & With CHX, applied with OSC ch adhesive system, immersed in $10 \% \mathrm{NaOCl}$ for $1 \mathrm{~h}$ \\
\hline
\end{tabular}

TSC: Two-step self-etch Clearfil SE ${ }^{\text {TM }}$, OSC: One-step self-etch Clearfil Tri S ${ }^{\text {TM }}$, CHX: $2 \%$ chlorhexidine gluconate

Table 3: Shear bond strength values for each treatment group (MPa)

\begin{tabular}{lllll}
\hline Treatment & Mean \pm SD & & & \\
\cline { 2 - 5 } & TSC & TSC+CHX & OSC & OSC+CHX \\
\hline Without $10 \% \mathrm{NaOCl}$ & $10.93 \pm 1.31 \mathrm{~A}$ & $11.67 \pm 1.76 \mathrm{AB}$ & $9.97 \pm 1.41 \mathrm{AB}$ & $10.19 \pm 1.44 \mathrm{AB}$ \\
With $10 \% \mathrm{NaOCl}$ & $10.08 \pm 0.45 \mathrm{AB}$ & $11.14 \pm 1.22 \mathrm{AB}$ & $8.62 \pm 0.85 \mathrm{~B}$ & $9.95 \pm 1.21 \mathrm{AB}$ \\
\hline
\end{tabular}

*Value with different superscript letters shows a significant difference at $\mathrm{p}<0.05$. TSC: Two-step self-etch Clearfil SE ${ }^{\mathrm{TM}}$, OSC: One-step self-etch Clearfil Tri $\mathrm{S}^{\mathrm{TM}}$, CHX: $2 \%$ chlorhexidine gluconate, SD: Standard deviation

that covered the dentin tubules and part of the exposed dentin tubules (Fig. 1). The dentin surface that was abraded with No. 600 silicon carbide abrasive paper, followed by application of $2 \%$ CHX (Fig. 2), showed no difference from the dentin tubules in specimens that were only abraded (Fig. 1).

The presence of strokes (scratches) was the result of abrasion with the No. 600 silicon carbide abrasive paper. The abraded dentin then followed by application of TSC primer displayed porous areas that were the dentin tubules (Fig. 2b). These areas were 2-4 $\mu \mathrm{m}$ in diameter and contained smear layer particles and collagen with demineralized dentin products that formed 2-5 $\mu \mathrm{m}$ acid globules. Fig. 2c shows an illustration of the continuation of the working phase as shown in Fig. 2a.

After abrasion, 2\% CHX and acid primer were applied, and we observed exposed 1-3 $\mu \mathrm{m}$ dentin tubules with acid globules that were dispersed evenly and uniformly in size $( \pm 1 \mu \mathrm{m})$. The element of Ca, P, C, and $\mathrm{O}$, the main components of dentin and $\mathrm{Cl}$, and an element presents in CHX $2 \%$ were almost completely absent on the dentin surface that was only abraded and the surface to which TSC primer was applied.

Fig. 3 displays the results of SEM and elemental analysis of the hybrid layer surface of the composite resin-dentin bond with the TSC adhesive system. SEM imaging of the composite resin-dentin bond with the TSC system showed varied hybrid layers. In the group without the application of $2 \%$ CHX (Fig. 3a), a hybrid layer of $5 \mu$ m thickness, with a 2-9 $\mu$ m-long resin tag, was observed.

The resin tag in the group without $2 \%$ CHX application appeared to be longer than that in the group with $2 \%$ CHX application (Fig. 3b). The group without the $2 \% \mathrm{CHX}$ application and $10 \% \mathrm{NaOCl}$ immersion (Fig. 3c) showed 3-8 $\mu \mathrm{m}$ pores along with a $30 \mu \mathrm{m}$-long resin tag, composed of the dissolved organic component (collagen) as well as inorganic components in the peri- and inter-tubular dentin.

The group with $2 \%$ CHX application and $10 \% \mathrm{NaOCl}$ immersion (Fig. 3d) showed more widely maintained organic components in the dentin than the group without the $2 \%$ CHX application and $10 \%$ $\mathrm{NaOCl}$ immersion did (Fig. 3c). Concentrated peritubular dentin, a $10-15 \mu \mathrm{m}$ resin tag, and $2-5 \mu \mathrm{m}$ pores were still observed in the dentin tubules.

Based on EDS analysis conducted with SEM imaging of the elemental content at the adhesive resin and dentin interface revealed the presence of $\mathrm{Ca}, \mathrm{P}, \mathrm{C}$ and $\mathrm{O}$ as the main composition of dentin, and $\mathrm{Cl}$ as an element

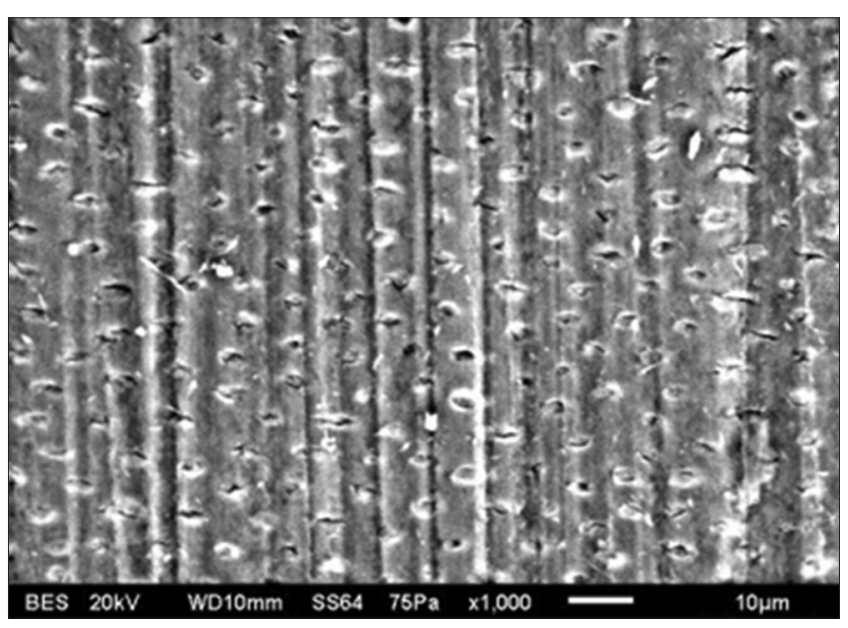

Fig. 1: Scanning electron microscopy $(\times 1000)$ after abrasion of the dentin surface with No. 600 silicon carbide abrasive paper

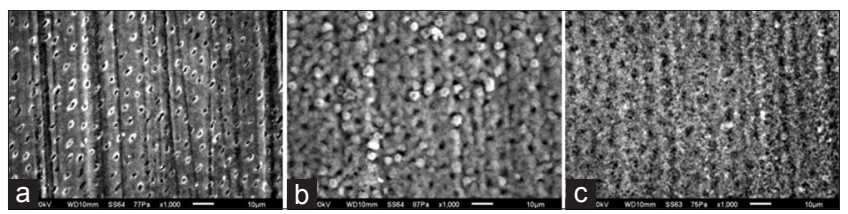

Fig. 2: Scanning electron microscopy $(\times 1000)$ of the dentin surface, (a) abraded dentin surface, with $2 \%$ chlorhexidine gluconate (CHX), (b) abraded dentin surface, with two-step selfetch (TSC) primer, (c) abraded dentin surface, with CHX and TSC primer

present in CHX 2\%, found in almost equal proportions (0.4-0.5\%) in all surfaces of composite resin- dentin interface.

Fig. 4 shows the results of the SEM and elemental analysis of the hybrid layer surface of the composite resin-dentin bond with the OSC adhesive system. The OSC group (Fig. 4a) showed a $5 \mu \mathrm{m}$-thick hybrid layer with an almost non-existent or short resin tag. The presence of black spaces indicated that adhesive resins had not properly infiltrated into the dentin. The OSC with $2 \%$ CHX group (Fig. 4b) showed a $5 \mu$ m-thick hybrid layer with an almost non-existent resin tag. In the OSC with $10 \% \mathrm{NaOCl}$ immersion group (Fig. 4c), the dissolved organic dentin 


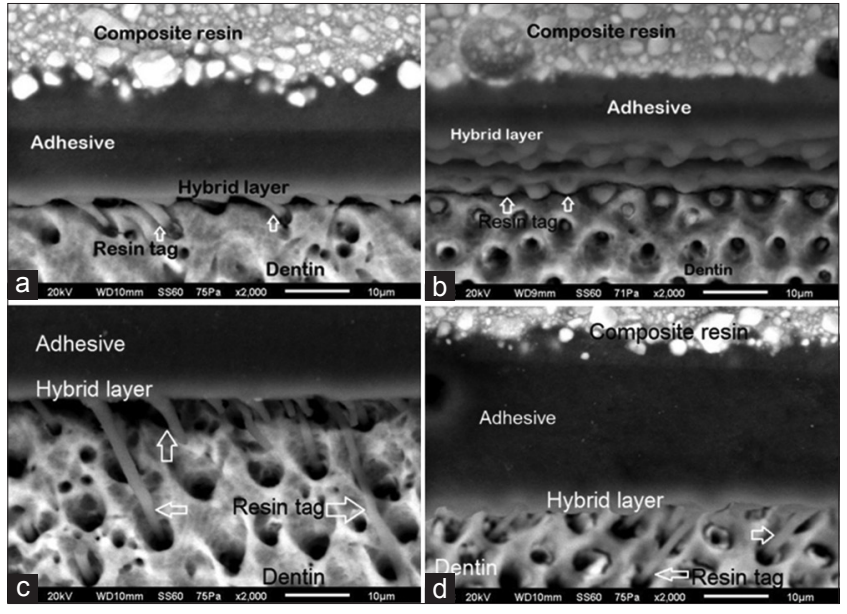

Fig. 3: Scanning electron microscopy $(\times 2000)$ of the hybrid layer of the composite resin-dentin bond with the two-step self-etch adhesive system, (a) without chlorhexidine gluconate (CHX) $2 \%$, (b) with $2 \% \mathrm{CHX}$ application, (c) without $2 \% \mathrm{CHX}$ application and immersed in $10 \% \mathrm{NaOCl}$ solution, (d) with $2 \% \mathrm{CHX}$ application and immersed in $10 \% \mathrm{NaOCl}$ solution

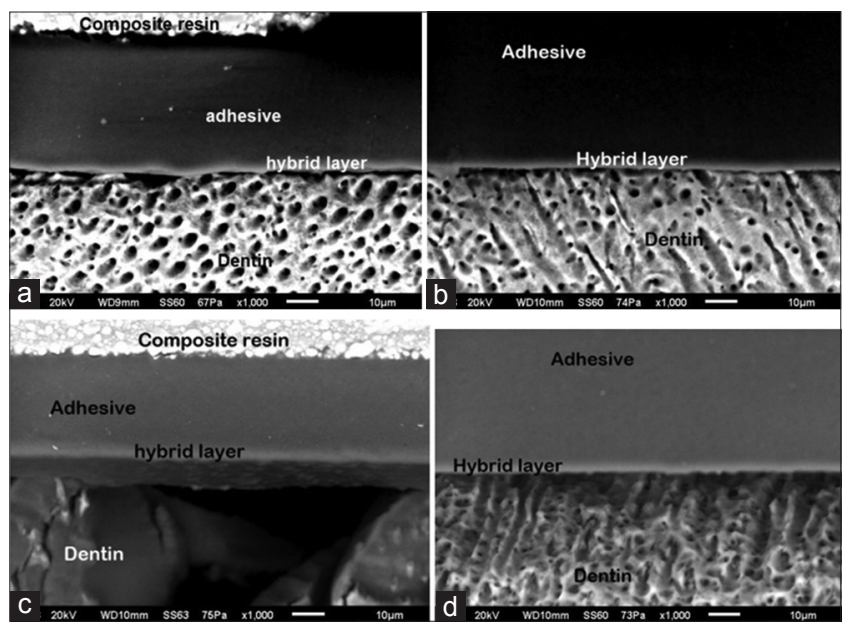

Fig. 4: Scanning electron microscopy $(\times 1000)$ of the composite resin-dentin bond with the one-step self-etch adhesive system, (a) without $2 \%$ chlorhexidine gluconate (CHX) application, (b) with $2 \%$ CHX application, (c) without $2 \%$ CHX application and immersed in $10 \% \mathrm{NaOCl}$ solution, (d) with $2 \% \mathrm{CHX}$ application and immersed in $10 \% \mathrm{NaOCl}$ solution

components were visible below the damaged and dissolved hybrid layer, with the presence of the large space between the dentin and adhesive layer. The dissolved organic component was also observed in the OSC group with $2 \% \mathrm{CHX}$ application and $10 \% \mathrm{NaOCl}$ immersion (Fig. 4d), although it was not as large as that of the OSC with $10 \% \mathrm{NaOCl}$ immersion group (Fig. 4c). Fig. 4d shows a broken bond between the adhesive resin and dentin.

EDS analysis of elemental content at the adhesive resin and dentin interface showed the presence of $\mathrm{Ca}, \mathrm{P}, \mathrm{C}$, and $\mathrm{O}$ as the main components of dentin and $\mathrm{Cl}$ as an element present in CHX2\%. Different percentages of $\mathrm{Cl}$ element were founded along the entire surface of the composite resin-dentin interface, with the largest percentage observed in the OSC group with $2 \% \mathrm{CHX}$ application and $10 \% \mathrm{NaOCl}$ immersion.

\section{DISCUSSION}

Although the increase was not statistically significant, 2\% CHX usage resulted in an increase in mean shear bond strength in the TSC
(Clearfil SE) group and OSC (Clearfil S3) group. This indicates that $2 \%$ CHX application may increase the shear strength of the composite resin-dentin bond when using self-etch adhesive systems. In contrast, several studies conducted by Shafiei et al. and Chaharom et al. have shown a decrease in the shear strength of the composite resin-dentin bond after the application of CHX $2 \%$, when using a self-etch adhesive system $[14,22]$. This inconsistency in findings may be caused by differences in the duration of 2\% CHX application, 2\% CHX application technique, composition of the adhesive system, testing method used, and specimen preparation $[14,22]$.

In the study by Shafiei et al., the duration of 2\% CHX application was $60 \mathrm{~s}$, whereas in the present study, the duration was $15 \mathrm{~s}$ [22]. The shorter duration of $2 \%$ CHX application does not affect the adhesive monomer's penetration to the dentin. However, the difference in application duration may affect the shear bond strength of the composite resin-dentin bond.

This hypothesis is supported by the findings of Collares et al., which suggested that the duration of application affected the shear bond strength [10]. In addition, Stanislawczuk et al. reported that an application time of $15 \mathrm{~s}$ was sufficient for inhibiting the degradation of the adhesive resin-dentin bond because the bond between $2 \%$ CHX and dentin collagen fibrils had already formed at that time $[11,23]$.

In the present study, we observed an increase in shear bond strength in all groups after $2 \%$ CHX application, although this increase was not statistically significant. This is consistent with the findings of Carrilho et al. who reported that $2 \% \mathrm{CHX}$ application may increase the shear strength of the composite resin-dentin bond [24]. CHX 10\% has a positive ionic charge (cation) that is powerful enough to allow it to bind with the phosphate cluster on dentin and has a strong affinity that can increase the surface energy of dentin [25]. 2\% CHX application after acid etching and before primer application on the self-etch adhesive system increases the primer's wet ability, which increases the adhesion; however, excess water needs to be removed by drying after $2 \%$ CHX application [26]

The adhesive system used in this study had a different composition than the adhesive system used by Shafiei et al. [22]. Clearfil SE is better than other TSCs because the MDP monomer can form an ionic bond with the calcium from dentin's hydroxyapatite and form nanolayers of calcium salt-MDP [27]. This nanolayering does not occur in other self-etch adhesive systems. In addition, the nanolayer formed is more resistant to dissolution than that formed in other adhesive systems. A calcium salt-MDP nanolayer is also formed when using Clearfil S3, although it not as prominent as the one formed with Clearfil SE $[27,28]$.

Among the groups with $2 \%$ CHX application and without $10 \% \mathrm{NaOCl}$ immersion, the shear strength of the composite resin-dentin bond with the TSC adhesive system was greater than that with the OSC adhesive system. A study by Knobloch et al. revealed that the composite resindentin bond strength with the TSC Clearfil SE Bond adhesive system (20.4 MPa) was higher than that with the OSC Clearfil S3 Bond adhesive system (16.5 MPa) [29]. However, a study conducted by Chaharom et al. showed that the composite resin-dentin bond strength did not differ significantly between the TSC Clearfil SE Bond (22.86 MPa) and the OSC Clearfil S3 Bond (22.13 MPa) adhesive systems [14]. According to Chaharom et al., this non-significant difference was because the same monomer, MDP, was used by both systems [16].

The mean shear bond strength was significantly different between the specimens using TSC without $2 \% \mathrm{CHX}$ and those using OSC without CHX $2 \%$, after immersion in $10 \% \mathrm{NaOCl}$. This indicates that the TSC adhesive system is more resistant to degradation than the OSC adhesive system because it contains a higher proportion of hydrophilic components than the OSC does [28-31].

The increase in shear bond strength after the application of $2 \%$ CHX found in this study was supported by SEM findings. A hybrid layer 
with a thickness of $5 \mu \mathrm{m}$ was observed when using the TSC adhesive system with $2 \%$ CHX application. In addition, a homogenous and even resin tag was also observed. This indicates that adhesive resin can infiltrate demineralized dentin, thus forming a resin tag that enables good bonding. The SEM image of the composite resin-dentin bond with the TSC adhesive system corresponded to the SEM image of the dentin surface after abrasion and before application of primer. The smear observed on dentin without the application of $2 \%$ CHX did not differ from the smear observed on dentin with the application of $2 \% \mathrm{CHX}$. However, a significant difference was observed after the primer was applied, with the smear layer interacting with the CHX 2\%. After the primer was applied, it also reacted with smear layer and $2 \%$ CHX. This finding can be explained by the results of a study by Hipolito et al., which revealed that $\mathrm{CHX}$ cation could bind to the phosphate group and calcium from hydroxyapatite, forming phosphate salt. The remaining cation can form a bond with the anion phosphate from MDP [32]. Moreover, this interaction does not interfere with the infiltration of the adhesive resin. This was supported by our finding that the resin tag still forms with a length of $10-15 \mu \mathrm{m}$, indicating the formation of an adequate adhesive resin-dentin bond.

In the OSC adhesive system, $2 \%$ CHX application did not interfere with the infiltration of adhesive monomer into the dentinal tubules. The resin tag formed was short, with a length of $\pm 2 \mu \mathrm{m}$, or almost non-existent. This was similar to the SEM findings in dentin without the application of CHX $2 \%$. This shows that an adequate bond can be achieved. This is also supported by the finding that the shear strength of the adhesive resin-dentin bond in the OSC adhesive system without $2 \%$ CHX application increased after the application of CHX $2 \%$, although this increase was not statistically significant.

In the TSC adhesive system with $10 \% \mathrm{NaOCl}$ immersion, the effect of the inhibition of collagen degradation was observed by comparing SEM imaging of the dentin surface without $2 \%$ CHX to the dentin surface with CHX 2\%. With 2\% CHX application, peritubular dentin inside the dentinal tubules was still present and undissolved, and the pores in the dentinal tubules decreased in size $(2-5 \mu \mathrm{m})$ because of the degradation process. This indicates that $2 \% \mathrm{CHX}$ protects the dentinal collagen matrix. In the OSC adhesive system, degradation in the groups with $2 \%$ CHX treatment was not as prominent as degradation in the group without 2\% CHX treatment. Among the groups without CHX 2\%, the group with the OSC adhesive system showed greater degradation in the composite resin-dentin bond than the group with the TSC adhesive system, after immersion in $10 \% \mathrm{NaOCl}$. This finding is also supported by the significant difference in mean shear bond strength between OSC and the TSC groups after immersion in $10 \% \mathrm{NaOCl}$. In addition to the lower shear bond strength, the OSC adhesive system was more prone to degradation than the TSC adhesive system was.

The EDS findings from the surface of abraded dentin, with the application of $2 \%$ CHX and primer (data not shown), revealed that the organic components of dentin in all the groups were primarily $\mathrm{C}$ and $\mathrm{O}$, constituting 14-36\%, compared to $\mathrm{Ca}$ and $\mathrm{P}$, which constituted $9-27 \%$. C, N, and $\mathrm{O}$ are the elements that make up the organic collagen matrix, which contains carboxyl $(-\mathrm{OOH})$, hydroxyl $(-\mathrm{OH})$, and amino $\left(-\mathrm{NH}_{2}\right)$ groups [33]. In contrast, Ca and $\mathrm{P}$ are the elements that make up hydroxyapatite, which has a chemical formula of $\left.\mathrm{Ca}_{10}\left(\mathrm{PO}_{4}\right)_{6}\right) \mathrm{H}_{2}$ [26]. The element $\mathrm{p}$ is the primary component of the monomer MDP in the adhesive region [28].

Other elements such as $\mathrm{Si}, \mathrm{Al}$, and $\mathrm{Mg}$ are considered contaminants from abrasive materials such as alumina $\left(\mathrm{Al}_{2} \mathrm{O} 3\right)$ and silica $\left(\mathrm{SiO}_{2}\right)$ that are incorporated during the preparation of the specimen. $\mathrm{Cl}$ was also detected on the dentin surface, with the highest percentage being present in the abraded surface with $2 \%$ CHX application (0.15\%). CHX was considered the source of this Cl. However, EDS only detects elements that are present on the surface and cannot detect elements underneath the dentin surface [34,35]. Elemental analysis from SEM/ EDS analysis of the composite resin-bonding surface revealed different
$\mathrm{Cl}$ contents, ranging from $0.4 \%$ to $0.5 \%$ and 0.26 to $1.02 \%$. These elements may be contained within $2 \%$ CHX or in the residue from soaking in the $1 \% \mathrm{NaOCl}$ used for preparing the specimens for SEM. Si was also detected in all groups (data not shown) and may have been derived from silica $\left(\mathrm{SiO}_{2}\right)$, which is the matrix particle on the adhesive resin Clearfil SE Bond and Clearfil S3.

The decrease in shear bond strength due to the smearing induced by $10 \% \mathrm{NaOCl}$ was not as high in the group treated with $2 \%$ CHX as in the group without $2 \%$ CHX treatment. This shows that the application of $2 \%$ CHX can inhibit the degradation process, resulting in greater shear bond strength in the group with $2 \%$ CHX application. The degradation still takes place, but at a much slower rate, and it is not as prominent as the degradation in the group without $2 \%$ CHX application. In theory, $2 \%$ CHX can protect the open collagen fibers that are generated by acid exposure and that have not been infiltrated by adhesive, thus prevent degradation of collagen fibers by MMP enzymes. MMP enzymes can be activated by the acid in the etching material and only degrade open collagen fibers. Another possibility is that the cation in 2\% CHX binds with the calcium and zinc ions that act as catalysts for MMP enzymes, thereby interfering with the catalytic activity $[10,23,24]$.

\section{CONCLUSIONS}

The shear strength of the composite resin-dentin bond is higher with the application of $2 \%$ CHX than without its application, although this difference was not statistically significant. SEM imaging in the specimens treated with $2 \%$ CHX shows less degradation compared to the specimens without 2\% CHX application. Thus, 2\% CHX may inhibit the degradation of the composite resin-dentin bond.

\section{ACKNOWLEDGMENT}

Publication of this manuscript is supported by Universitas Indonesia.

\section{REFERENCES}

1. Chesterman J, Jowett A, Gallacher A, Nixon P. Bulk-fill resin-based composite restorative materials: A review. Br Dent J 2017;222:337-44

2. Summit JB, Robins JW, Hilton TJ, Schwartz RS. Fundamentals of Operative Dentistry: A Contemporary Approach. $3^{\text {rd }}$ ed. Chicago, USA: Quintessence Pub; 2006.

3. Dennis, Abidin T. Degradation of resin-dentin bonds and current methods of its prevention. Indian J Restor Dent 2013;2:1-7.

4. Nagappan K, Yamjala K, Sathyaseelan M, Byran G. Stability evaluation of tartrazine by liquid chromatography-diode array detector and highresolution electron spray ionization quadrupole time-offlight mass spectrometry/mass spectrometry analysis. Asian J Pharm Clin Res 2017; 10:295-9

5. Feitosa VP, Leme AA, Sauro S, Correr-Sobrinho L, Watson TF, Sinhoreti MA, et al. Hydrolytic degradation of the resin-dentine interface induced by the simulated pulpal pressure, direct and indirect water ageing. J Dent 2012;40:1134-43

6. Toledano M, Yamauti M, Osorio E, Osorio R. Bleaching agents increase metalloproteinases-mediated collagen degradation in dentin. J Endod 2011;37:1668-72.

7. Serkies KB, Garcha R, Tam LE, De Souza GM, Finer Y. MMP inhibitor modulates esterase-catalyzed degradation of resin-dentin interfaces. Dent Mater 2016;32:1513-23.

8. Kang HJ, Moon HJ, Shin DH. Effect of different chlorhexidine application times on microtensile bond strength to dentin in class I cavities. Restor Dent Endod 2012;37:9-15.

9. Perdigão J. Dentin bonding-variables related to the clinical situation and the substrate treatment. Dent Mater 2010;26:e24-37.

10. Collares FM, Rodrigues SB, Leitune VC, Celeste RK, Borba de Araújo F, Samuel SM. Chlorhexidine application in adhesive procedures: A meta-regression analysis. J Adhes Dent 2013;15:11-8.

11. Stanislawczuk R, Reis A, Loguercio AD. A 2-year in vitro evaluation of a chlorhexidine-containing acid on the durability of resin-dentin interfaces. J Dent 2011;39:40-7.

12. Borges FM, de Melo MA, Lima JP, Zanin IC, Rodrigues LK. Antimicrobial effect of chlorhexidine digluconate in dentin: In vitro and in situ study. J Conserv Dent 2012;15:22-6.

13. Mohammadi Z, Abbott PV. The properties and applications of 
chlorhexidine in endodontics. Int Endod J 2009;42:288-302

14. Chaharom ME, Ajami AA, Kimyai S, Abbasi A. Effect of chlorhexidine on the shear bond strength of self-etch adhesives to dentin. Afr $\mathrm{J}$ Biotechnol 2011:10:10054-57.

15. Moon PC, Weaver J, Brooks CN. Review of MMPs' effect on the hybrid dentin bond layer stability and chlorhexidine clinical use to prevent bond failure. Open Dent J 2010;4:147-52.

16. Sharma V, Nainan MT, Shivanna V. The effect of cavity disinfectants on the sealing ability of dentin bonding system: An in vitro study. J Conserv Dent 2009;12:109-13.

17. Sharma V, Rampal P, Kumar S. Shear bond strength of composite resin to dentin after application of cavity disinfectants-SEM study. Contemp Clin Dent 2011;2:155-9.

18. Amaral FL, Colucci V, Palma-Dibb RG, Corona SA. Assessment of in vitro methods used to promote adhesive interface degradation: A critical review. J Esthet Restor Dent 2007;19:340-53.

19. Garbui BU, Botta SB, Reis AF, Matos AB. Comparison of chemical aging and water immersion time on durability of resin-dentin interface produced by an etch-and-rinse adhesive. J Contemp Dent Pract 2012;13:464-71.

20. Dayem RN. A novel method for removing the collagen network from acid-etched dentin by neodymium: Yttrium-aluminum-garnet laser. Lasers Med Sci 2009;24:93-9.

21. Kim YH, Shin DH. Effect of chlorhexidine application on the bond strength of resin core to axial dentin in endodontic cavity. Restor Dent Endod 2012;37:207-14.

22. Shafiei F, Alikhani A, Alavi AA. Effect of chlorhexidine on bonding durability of two self-etching adhesives with and without antibacterial agent to dentin. Dent Res J (Isfahan)2013;10:795-801.

23. Loguercio AD, Stanislawczuk R, Polli LG, Costa JA, Michel MD, Reis A. Influence of chlorhexidine digluconate concentration and application time on resin-dentin bond strength durability. Eur J Oral Sci 2009; 117:587-96.

24. Carrilho MR, Geraldeli S, Tay F, de Goes MF, Carvalho RM, Tjäderhane L, et al. In vivo preservation of the hybrid layer by chlorhexidine. J Dent Res 2007;86:529-33.
25. Darabi F, Eftekhari M. Effect of chlorhexidine on microleakage of composite restorations. J Dent 2009;6:16-22.

26. Boruziniat A, Babazadeh M, Gifani M. Effect of chlorhexidine application on bond durability of a filled-adhesive system. J Dent Mater Tech 2013;2:6-10

27. Yoshida Y, Yoshihara K, Nagaoka N, Hayakawa S, Torii Y, Ogawa T, et al. Self-assembled Nano-layering at the Adhesive interface. J Dent Res 2012;91:376-81

28. Feitosa VP, Pomacóndor-Hernández C, Ogliari FA, Leal F, Correr AB, Sauro S. Chemical interaction of 10-MDP (methacryloyloxi-decyldihydrogen-phosphate) in zinc-doped self-etch adhesives. J Dent 2014:42:359-65.

29. Knobloch LA, Gailey D, Azer S, Johnston WM, Clelland N, Kerby RE. Bond strengths of one-and two-step self-etch adhesive systems. J Prosthet Dent 2007;97:216-22.

30. Landuyt KV, Munck JD, Coutinho E, Peumans M, Lambrechts P, Van-Meerbeek B. Bonding to dentine: Smear layer and the process of hybridization. In: Eliades G, Watts DC, Eliades T, editors. Dental Hard Tissues and Bonding: Interfacial Phenomena and Realated Properties. Heidelberg: Springer; 2005.

31. Sacramento PA, Sampaio CS, Carvalho FG, Pascon FM, Borges AF, Alves $\mathrm{MC}$, et al. Influence of $\mathrm{NaOCl}$ irrigation and water-storage on degradation and microstructure of resin-dentin interface. J Adhes Dent 2013;47:117-24.

32. Di Hipólito V, Rodrigues FP, Piveta FB, Azevedo Lda C, Bruschi Alonso RC, Silikas N, et al. Effectiveness of self-adhesive luting cements in bonding to chlorhexidine-treated dentin. Dent Mater 2012;28:495-501.

33. Perdigao J, Swift EJ Jr, Denehy GE, Wefel JS, Donly KJ. In vitro bond strengths and SEM evaluation of dentin bonding systems to different dentin substrates. Dent Res 1994;73:44-55.

34. Yuan Y, Shimada Y, Ichinose S, Tagami J. Qualitative analysis of adhesive interface nanoleakage using FE-SEM/EDS. Dent Mater 2007:23:561-9.

35. Goldstein J, Newbury DE, Joy DC, Lyman CE, Echlin P, Lifshin E, et al. SEM and X-ray Microanalysis. $3^{\text {rd }}$ ed. New York: Kluwer academic/ Plenum Publishers; 2003. 